\title{
Detection of Oil Palm Root Penetration by Agrobacterium-Mediated Transformed Ganoderma boninense, Expressing Green Fluorescent Protein
}

\author{
Nisha Govender and Mui-Yun Wong
}

First and second authors: Laboratory of Plantation Crops, Institute of Tropical Agriculture, and second author: Department of Plant Protection, Faculty of Agriculture, Universiti Putra Malaysia, 43400 Serdang, Selangor, Malaysia. Accepted for publication 27 November 2016.

\begin{abstract}
A highly efficient and reproducible Agrobacterium-mediated transformation protocol for Ganoderma boninense was developed to facilitate observation of the early stage infection of basal stem rot (BSR). The method was proven amenable to different explants (basidiospore, protoplast, and mycelium) of G. boninense. The transformation efficiency was highest $(62 \%)$ under a treatment combination of protoplast explant and Agrobacterium strain LBA4404, with successful expression of an hyg marker gene and gus-gfp fusion gene under the control of heterologous p416 glyceraldehyde 3-phosphate dehydrogenase promoter. Optimal transformation conditions included a 1:100 Agrobacterium/ explant ratio, induction of Agrobacterium virulence genes in the presence
\end{abstract}

ABSTRACT of $250 \mu \mathrm{m}$ acetosyringone, co-cultivation at $22^{\circ} \mathrm{C}$ for 2 days on nitrocellulose membrane overlaid on an induction medium, and regeneration of transformants on potato glucose agar prepared with $0.6 \mathrm{M}$ sucrose and $20 \mathrm{mM}$ phosphate buffer. Evaluated transformants were able to infect root tissues of oil palm plantlets with needle-like microhyphae during the penetration event. The availability of this model pathogen system for BSR may lead to a better understanding of the pathogenicity factors associated with $G$. boninense penetration into oil palm roots.

Additional keywords: Basidiomycetes.
Ganoderma boninense is the primary agent of basal stem rot (BSR) disease (Ho and Nawawi 1985; Thompson 1931; Utomo et al. 2005) and has been continuously affecting the oil palm industry over the years. In mature palm trees, the fungus is able to infect up to $80 \%$ of the stand (Turner and Gillbanks 2003), limiting productive lifespan of the crop. Several G. boninense pathogenesis studies have improved the understanding of BSR development. Paterson (2007) demonstrated $G$. boninense infection via direct root-pathogen contact only. The soilborne $G$. boninense uses the root system to establish along the palm stem base, evident with visible formation of fruiting bodies (Ariffin et al. 2000; Sundram et al. 2011). In addition, microscopic examination of infected palm at the cellular level by Rees et al. (2009) revealed acquisition of biotrophic nutrition by the pathogen during colonization. G. boninense degrades lignin to weaken the rigid plant cell wall structure prior to starch consumption. The same study described G. boninense as a hemibiotroph, because the pathogen is able to switch from biotrophic nutrition (asymptomatic host) into necrotroph nutrition (symptomatic host) during the later stages of disease development. Generally, there are three key events held by hemibiotrophs during host colonization: (i) penetration, (ii) nutrient absorption at the expense of host, and (iii) host death (Rees et al. 2009; Turner 1981). Although the second and third components are well characterized in G. boninense pathogenesis, visualization and characterization of host penetration remain elusive.

The genetic transformation of a pathogen provides a means to resolve the many mechanisms underlying disease development (Pardo et al. 2002; Wang et al. 2010). Several successful

Corresponding author: N. Govender; E-mail address: nish_277@yahoo.com

*The $\boldsymbol{e}$-Xtra logo stands for "electronic extra" and indicates that two supplementary figures are published online.

(C) 2017 The American Phytopathological Society transformation protocols have been established for Ganoderma spp. (Sharma and Kuhad 2010), including G. lucidum (Sun et al. 2001), G. weberianum (Zhou et al. 2015), and G. multipileum (Chou and Tzean 2016). Various techniques such as electroporation, Agrobacterium-mediated transformation (AMT), and biolistic transformation are employed to transform species within the fungal kingdom (Michielse et al. 2005). Despite the robust availability of resources, AMT is highly favored due to cost effectiveness, conserved integration of the target gene (Zhu et al. 2000), and wide choices of explants amendable to the technique. Agrobacterium tumefaciens, a gram-negative, pathogenic bacterium, naturally integrates part of its DNA sequence into a host's genome. The transfer DNA (T-DNA) machinery recognizes host phenolics which, in turn, activates its virulence genes to complete the mechanism (Michielse et al. 2005). More than 130 different fungal species, including zygomycetes, ascomycetes, and basidiomycetes, have been amendable to an AMT system, as indicated through successful regeneration of transformants (Ali and Bakkeren 2011; Mora-Lugo et al. 2014). Presently, AMT is used as an integrated tool in modern fungal research even though the protocols are complex and species specific (Wang et al. 2008). Although AMT protocols are applicable for the family Ganodermatacea, none are described for $G$. boninense. The main objective of this study was to develop an efficient AMT system for the pathogenic fungus $G$. boninense to express the green florescent protein (GFP) and determine the penetrating structure employed by the pathogen during the early stage of BSR.

\section{MATERIALS AND METHODS}

Bacterial strains. Escherichia coli strain JM109 was used for large-scale plasmid amplification. Plasmid DNA was extracted using a High-Speed Plasmid Mini Kit (Geneaid Biotech Ltd.) following the manufacturer's instructions. The following A. tumefaciens strains retrieved from stock collections (Laboratory of Crop Plantations, Institute of Tropical Agriculture, Universiti Putra Malaysia) were used in cocultivation procedures: LBA4404, 
EHA101, EHA105, and GV3101. The GV3101 strain was a kind gift from Dr. Hann-Ling Wong, University Tunku Abdul Rahman, Perak, Malaysia. The minimum inhibitory concentration against kanamycin for all transformed strains was $50 \mu \mathrm{g} / \mathrm{ml}$, except for EHA101, which was $200 \mu \mathrm{g} / \mathrm{ml}$.

Fungal explants. A virulent strain of $G$. boninense (T10), provided by Applied Agricultural Resources, Selangor, Malaysia, was used for transformation. Three types of explants were utilized in this study: protoplast, basidiospore, and mycelium. Mycelia grown on a nitrocellulose membrane overlaid on malt extract agar (MEA) (Merck) supplemented with 2\% lignin alkali (SigmaAldrich) was harvested as cubes of 0.5 by $0.5 \mathrm{~cm}$ from the leading edge of the colony at day 5 after inoculation. For production of basidiospores, a basidiocarp (mature fruiting body) was artificially obtained in glasshouse conditions (Govender et al. 2016). A fully mature basidiocarp, manifesting a stipe, bracketed cap with visible hymenium on its underside, and deep red coloration on its outer surface, was utilized for subsequent basidiospore isolation. The visible hymenium region of the basidiocarp was cut into small pieces and dropped into deionized water. The mixture was subjected to agitation at $150 \mathrm{rpm}$ for $20 \mathrm{~min}$ followed by filtration using glasswool. The resultant filtrate was centrifuged at $1,000 \times g$ for $1 \mathrm{~min}$. The supernatant was directly diluted to the required concentration for the transformation procedure. For protoplast isolation, enzymatic digestion was performed using a commercial lysing enzyme (L1412) from Trichoderma harzianum (SigmaAldrich). Protoplasts were obtained from 3-day-old mycelia digested in lysing enzyme $(10 \mathrm{mg} / \mathrm{ml})$ prepared in $0.6 \mathrm{M}$ potassium chloride and $20 \mathrm{mM}$ dipotassium phosphate buffer ( $\mathrm{pH}$ 5.4). The mixture was incubated for $3 \mathrm{~h}$ at $30^{\circ} \mathrm{C}$, then filtered with Whatman paper number 4 (Sigma-Aldrich). The basidiospore and protoplast regeneration assessments were performed prior to the transformation procedure (Govender et al. 2016). Both basidiospore and protoplast suspensions were adjusted to the required concentrations using the hemocytometer.

Plasmid construction. Vector pCAMBIA 1304, provided by Dr. Sreeramanan Rahman (Universiti Sains Malaysia, Pulau Pinang, Malaysia) was modified as described by Sharma and Kuhad, (2010) prior to transformation into Agrobacterium strains using the heat-shock method (Wang et al. 2010). Vector p416 ATCC87360 (Addgene) harboring the glyceraldehyde 3-phosphate dehydrogenase ( $g p d$ ) fungal promoter (Mumberg et al. 1995) was excised using a $S a c I$ and $X b a I$ double-enzyme digestion following the manufacturer's instructions (Fast Digest; Thermo Scientific). The binary vector pCAMBIA 1304 was digested with the same enzymes. The double-digested products of p416 were subjected to gel electrophoresis, followed by excision of the 281-bp DNA fragment harboring the gpd promoter using the GeneJet Gel Extraction Kit (Thermo Scientific), as described by the manufacturer's protocol. The generated fragment was ligated into the multiple cloning site between the left and right T-DNA borders of pCAMBIA 1304 using the Rapid DNA ligation kit (Thermo Scientific). The resultant modified pCAMBIA 1304 (12,643 bp) was cloned into E. coli (JM109) for large-scale amplification and verified via DNA sequencing (First Base).

Growth media and culture conditions. The Agrobacterium strains were grown on Luria-Bertani medium amended with kanamycin, as required (50 or $200 \mu \mathrm{g} / \mathrm{ml}$ ). Minimal medium (MM) was composed of $10 \mathrm{mM} \mathrm{K}_{2} \mathrm{HPO}_{4}, 10 \mathrm{mM} \mathrm{NaH}_{2} \mathrm{PO}_{4}, 2.5 \mathrm{mM} \mathrm{KCl}$, $2 \mathrm{mM} \mathrm{MgSO}_{4}, 0.7 \mathrm{mM} \mathrm{CaCl}_{2}, 9 \mu \mathrm{M} \mathrm{FeSO}_{4}, 4 \mathrm{mM}\left(\mathrm{NH}_{4}\right)_{2} \mathrm{SO}_{4}$, and $10 \mathrm{mM}$ glucose, $\mathrm{pH}$ 7.0. The induction medium (IM) was prepared by adding the following to MM: $0.5 \%$ (wt/vol) glycerol, $250 \mu \mathrm{M}$ acetosyringone, and $40 \mathrm{mM} 2$-(N-morpholino) ethanesulfonic acid, $\mathrm{pH}$ 5.3. Induction agar was prepared as induction medium with $2 \%$ agar. The selection media used depended on the explant source; potato dextrose agar (PDA) for basidiospore, potato glucose agar (PGA) for protoplast, and MEA for mycelium. Selection media were supplemented with cefotaxime at $100 \mu \mathrm{g} / \mathrm{ml}$ and hygromycin (hyg) B at $200 \mu \mathrm{g} / \mathrm{ml}$. All induction and selection media for protoplast explants only were further supplemented with $0.6 \mathrm{M}$ sucrose and $20 \mathrm{mM}$ phosphate buffer, which served as the osmotic stabilizer. All chemicals and medium, unless stated otherwise were purchased from Sigma-Aldrich.

Transformation procedure. The A. tumefaciens cultures (LBA4404, EHA101, EHA103, and GV3103) were grown in MM supplemented with kanamycin (50 or $200 \mu \mathrm{g} / \mathrm{ml}$ ) at $28^{\circ} \mathrm{C}$ with shaking $(150 \mathrm{rpm})$ overnight. Each culture was centrifuged at $1,000 \times$ $g$ for $5 \mathrm{~min}$; the resultant pellet was suspended in IM supplemented with kanamycin and grown for $8 \mathrm{~h}$ under similar conditions. Explants of $G$. boninense were freshly harvested and prepared in deionized water at the following concentrations: mycelia cubes on nitrocellulose membrane (10 cubes $/ \mathrm{ml})$ and basidiospores and protoplasts at $10^{4}$ to $10^{5}$ per milliliters each. The Agrobacterium (optical density at $600 \mathrm{~nm}=0.05$ to 0.1 ) and explant mixture prepared at a 1:100 ratio with all possible combinations was spread on a nitrocellulose membrane overlaid on the induction agar. The plate was incubated at $22^{\circ} \mathrm{C}$ for 2 days; then, the nitrocellulose membrane was transferred onto a selection agar and grown at $28^{\circ} \mathrm{C}$ until visible transformant colonies appeared (approximately a week). Transformation efficiency was determined by dividing the number of transformed single colonies on the selection plate by the number of wild-type colonies on the control plate. Nontransformed mycelia, basiodiospores, and protoplasts (wild type) were inoculated on nonsupplemented PDA as controls. All transformants were species verified using the Ganoderma selective medium, Malaysian Palm Oil Board, Selangor, Malaysia (Ariffin et al. 2000) which forms a brown ring around colonies of $G$. boninense only (Supplementary Fig. S1). In addition, we performed polymerase chain reaction (PCR) for amplification of the $G$. boninense internal transcribed spacer region using the following primers: forward, $5^{\prime}$-gtgggttatagatcgtgtgga- $3^{\prime}$ and reverse, $5^{\prime}$-ttctaaccgtcccgttattgg- $3^{\prime}$.

Because the transformant derived from protoplast explant cocultivated with Agrobacterium LBA4404 showed the best transformation efficiency coupled with good GFP florescence, we further optimized the following parameters for this particular combination: Agrobacterium strain/explant ratio, cocultivation temperature, and cocultivation period. The protoplast suspension was mixed with Agrobacterium LBA4404 at 1:1, 1:10, 1:100, and 1:1,000 (Agrobacterium/explant) volume ratios. Cocultivation temperature was set at 20,22 , and $26^{\circ} \mathrm{C}$ for 2 days using the Agrobacterium LBA4404 and protoplast explant (1:100) combination. Cocultivation period for Agrobacterium LBA4404 and protoplast explant at 1:100 ratio was also evaluated by incubating mixtures at $22^{\circ} \mathrm{C}$ for $1,2,3,4$, and 5 days. All cocultivation mixtures were transferred to nitrocellulose membrane overlaid on induction agar and incubated with the stated modifications using the same transformation procedure. The transformation efficiency was determined as described earlier.

Molecular analysis of $\boldsymbol{G}$. boninense transformants. The integration of T-DNA and gene copy number of GFP was determined for protoplast-LBA4404, basidiospore-GV3101 and mycelia-EHA101-derived transformants via PCR and quantitative (q)PCR. The G. boninense transformants and wild-type isolate were grown on nitrocellulose membrane overlaid on selection media and PDA, respectively, for 5 days. The harvested mycelia were ground into fine powders in liquid nitrogen. DNA was extracted using a GeneJet Genomic DNA Purification Kit (Thermo Scientific), following the manufacturer's instructions. In total, $50 \mathrm{ng}$ of fungal genomic DNA and $10 \mathrm{ng}$ of plasmid pCAMBIA1304 were used as template and positive control, respectively, throughout all amplifications. To verify the T-DNA integration, PCR analyses were performed using Hygr (Hyg F and Hyg R) and Gus-gfpr (Gus-gfp F and Gus-gfp R) cassette primers (Table 1). The PCR program was set at $94^{\circ} \mathrm{C}$ for $5 \mathrm{~min} ; 35$ cycles of $94^{\circ} \mathrm{C}$ for $60 \mathrm{~s}, 58^{\circ} \mathrm{C}$ for $30 \mathrm{~s}$, and $72^{\circ} \mathrm{C}$ for $30 \mathrm{~s}$; and final extension at $72^{\circ} \mathrm{C}$ for $3 \mathrm{~min}$. PCR Master Mix (2×) (Dream Taq; Thermo Scientific), was fixed at a final 
volume of $50 \mu \mathrm{l}$ with $400 \mathrm{nM}$ each forward and reverse primer. All PCR assays were carried out using thermal cycler C1000 Touch (Bio-Rad), and the PCR products were analyzed on $1.8 \%$ agarose gel stained with RedSafe dye (Intron Biotechnology).

As for the determination of gene copy number, genomic DNA extracted from both $G$. boninense wild-type isolate and transformants were used as templates, while plasmid pCAMBIA1304 was used as the positive control. The PCR product of the GFP fragment was run parallel for extrapolation of standard curve. The GFP fragment number in each transformant was determined as described by Dorak (2007). The number of GFP molecular copies for the standard curve was determined by dividing the concentration of DNA product (nanograms) by mass. A standard curve constructed from serial dilutions (10-fold differences) was used to determine GFP copy number in $G$. boninense transformants. The qPCR was performed in triplicate with $80 \mathrm{ng}$ of fungal genomic DNA in a $20-\mu \mathrm{l}$ reaction using a Green Real-Time PCR Master Mix (2x) kit (RealMOD) and CFX96 Touch Real-Time PCR Detection System (Bio-Rad). The final concentration of primers was $500 \mathrm{nM}$, and the reaction yielded a 179-bp DNA fragment. All reactions were performed under the following conditions: $94^{\circ} \mathrm{C}$ for $5 \mathrm{~min}$; 35 cycles of $94^{\circ} \mathrm{C}$ for $60 \mathrm{~s}, 60^{\circ} \mathrm{C}$ for $30 \mathrm{~s}$, and $72^{\circ} \mathrm{C}$ for $30 \mathrm{~s}$; and final extension at $72^{\circ} \mathrm{C}$ for $3 \mathrm{~min}$. Melt-curve analysis was performed to verify the absence of primer-dimer products.

$\beta$-Glucuronidase-GFP expression in $G$. boninense transformants. Fluorescence associated with GFP in $G$. boninense transformants was monitored using an Olympus FV1000 confocal laserscanning microscope (Olympus America Inc.). Thin mycelia sections (6 by $6 \mathrm{~mm}$ ) from the leading edge of 5-day-old transformant growing on selective media were mounted in water prior to microscopic examination.

Artificial infection of oil palm plantlets. The protoplast LBA4404-derived $G$. boninense transformant was grown on PGA for 5 days. Oil palm roots harvested from 5-year-old trees were utilized as substrate for preparation of inoculum. Oil palm roots ( 2 to $3 \mathrm{~cm}$ in diameter) were washed thoroughly, dried at $80^{\circ} \mathrm{C}$ for 3 days, and ground into a fine powder. Solidifying media composed of glucose (35 g/liter) and 5\% Bacto agar were added to each $100 \mathrm{~g}$ of oil palm root powder at a $1: 1(\mathrm{vol} / \mathrm{wt})$ ratio. The mixture was autoclaved at $121^{\circ} \mathrm{C}$ for $20 \mathrm{~min}$ and left to cool at room temperature. The semisolid media was shaped into balls of 2 to $3 \mathrm{~cm}$ in size using a sterilized metal spatula. Approximately two to three pieces of mycelia cubes $(0.5$ by $0.5 \mathrm{~mm})$ were added to each ball. The balls were incubated in the dark at $26 \pm 2^{\circ} \mathrm{C}$ for a week. Only balls fully colonized with mycelia were utilized for subsequent artificial infection of oil palm plantlet. Oil palm plantlets (5 weeks old) were grown under sterile tissue culture conditions in Gamborg B medium supplemented with 1-naphthaleneacetic acid at $0.1 \mathrm{mg} / \mathrm{liter}$ (Tarmizi 2002). Artificial inoculation of oil palm roots was performed on plantlets with a visible mass of roots. The edge of the oil palm plantlet root system was partially lifted out from the growing medium to create aeration. Balls of inocula were attached on aerated root surface by exerting a gentle pressure on the site of infection to secure the position of the inoculum on the roots. All infected plantlets were grown at $27^{\circ} \mathrm{C}$ in the dark, with shaking at $90 \mathrm{rpm}$. At 1 and 2 weeks postinoculation, root cross-sections

TABLE 1. Primer sequences for polymerase chain reaction (PCR) and quantitative PCR analysis of wild and transformant Ganoderma boninense

\begin{tabular}{lllc}
\hline Number & Primer name & \multicolumn{1}{c}{ Sequence $\left(5^{\prime}-3^{\prime}\right)$} & Product size $(\mathrm{bp})$ \\
\hline 1 & Hyg F & GCTCTGATAGAGTTGGTC & 806 \\
& Hyg R & CGTCTGTCGAGAAGTTT & $\ldots$ \\
2 & Gus-gfp F & GTCAAGTTTGAGGGAGAC & 1,395 \\
& Gus-gfp R & CATCTCTTCAGCGTAAGG & $\ldots$ \\
3 & Gfp F & TTTCTGTCAGTGGAGAGG & 179 \\
& Gfp R & GCTCTTGAAGAAGTCGTG & $\ldots$ \\
\hline
\end{tabular}

( 2 to $5 \mathrm{~mm}$ ) and root surface longitudinal sections of the oil palm plantlets were prepared for microscopic examination using the confocal laser microscopy equipped with filter blocks for GFP $(488 \mathrm{~nm})$ and root autofluorescence $(546 \mathrm{~nm})$, as described by Li et al. (2013). The broadband fiber connection was set at 415- to 635-nm lasers with a single fiber-type combiner. All digital images obtained were processed by OlyVIA, version 3 .

\section{RESULTS}

AMT of G. boninense. We tested three explant types (protoplast, basidiospore, and mycelia) and four Agrobacterium strains (LBA4404, EHA101, EHA105, and GV3103) at all possible combinations under the following conditions: cocultivation period of 2 days at $22^{\circ} \mathrm{C}$, with Agrobacterium/explant ratio set at 1:100. Depending on the explant types and Agrobacterium strains, transformation efficiency was 2 to $62 \%$ (Table 2). Of the three explant types utilized in this study, and using the conditions described above, protoplasts cocultivated with Agrobacterium strain LBA4404 showed the highest transformation efficiency $(62 \%)$, followed by basidiospore cocultivated with Agrobacterium strain GV3103 (52\%). In comparison with protoplast and basidiospore explant types, mycelium was least efficient; cocultivation with Agrobacterium EHA101, relative to other strains, showed the highest transformation efficiency (12\%).

Cocultivation of protoplasts with the four different Agrobacterium strains yielded transformation efficiency of 35 to $62 \%$, which was relatively higher than basidiospore and mycelium at 40 to 52 and 2 to 12\%, respectively (Table 2). The effect of Agrobacterium strain on transformation efficiency differed greatly with the different explants types used for cocultivation. Regeneration of transformants from basidiospores and protoplasts required approximately 2 weeks for formation of visible fungal colonies, and five subsequent subcultures regenerated successfully. In contrast, though cocultivation of Agrobacterium and mycelia showed successful transformation, poor regeneration of subcultures from the primary transformant was evident (data not shown).

Based on the results obtained from Table 2, we selected the most efficient explant-Agrobacterium pairing (evident with the highest transformation efficiency), protoplast and Agrobacterium LBA4404, for further optimization of the following parameters: cocultivation period, cocultivation temperature, and Agrobacterium/explant ratios. Transformation efficiency was relatively good (62\%) at the 1:100 Agrobacterium/explant ratio. As the concentration of Agrobacterium increased by 10 -fold increments, transformation efficiency decreased from $12 \%$ at $1: 10$ to $0 \%$ at $1: 1$

TABLE 2. Transformation efficiency (TE) of Ganoderma boninense at all possible combinations of Agrobacterium strains and fungal explants ${ }^{\mathrm{a}}$

\begin{tabular}{llcc}
\hline G. boninense explant & Strain & TE $(\%)^{\mathrm{b}}$ & Regen $^{\mathrm{c}}$ \\
\hline Protoplast & LBA4404 & 62 & Yes \\
& GV3101 & 46 & Yes \\
& EHA101 & 32 & Yes \\
Basidiospore & EHA105 & 35 & Yes \\
& LBA4404 & 40 & Yes \\
& GV3101 & 52 & Yes \\
EHA101 & 44 & Yes \\
Mycelium & EHA105 & 48 & Yes \\
& LBA4404 & 2 & No \\
& GV3101 & 5 & No \\
& EHA101 & 12 & No \\
& EHA105 & 7 & No
\end{tabular}

a All transformations were performed using the 1:100 Agrobacterium/explant mixture cocultivated on a nitrocellulose membrane overlaid on an induction medium for 2 days at $22^{\circ} \mathrm{C}$, then transferred onto a selection medium and incubated at $28^{\circ} \mathrm{C}$ for a week.

b Verified by hygromycin B selection.

c Regeneration at subsequent subcultures. 
Agrobacterium/explant ratio (Fig. 1A). At 1:1,000 Agrobacterium/ explant ratio, transformation efficiency was zero. A cocultivation at $22^{\circ} \mathrm{C}$ for 2 days showed the highest transformation efficiency at $63 \%$, followed by 3 days with a transformation efficiency of $31 \%$ (Fig. 1B). A period of 2 to 3 days was ideal for the transfer of T-DNA without compromising its ability to regenerate latter. A short period of 1 day showed poor (7\%) transformation efficiency, while no transformants were obtained for incubation periods of 4 to 5 days (data not shown). Cocultivation temperatures of 22,24 , and $26^{\circ} \mathrm{C}$ were evaluated. At 22 and $24^{\circ} \mathrm{C}$, the transformation efficiency was 62 and $60 \%$, respectively. However, at $26^{\circ} \mathrm{C}$, transformation was not successful (Fig. 1C).

Selection media affected the regeneration of transformants. Wild-type $G$. boninense basidiospores, protoplasts, and mycelia could be grown on PDA. However, the protoplast-derived

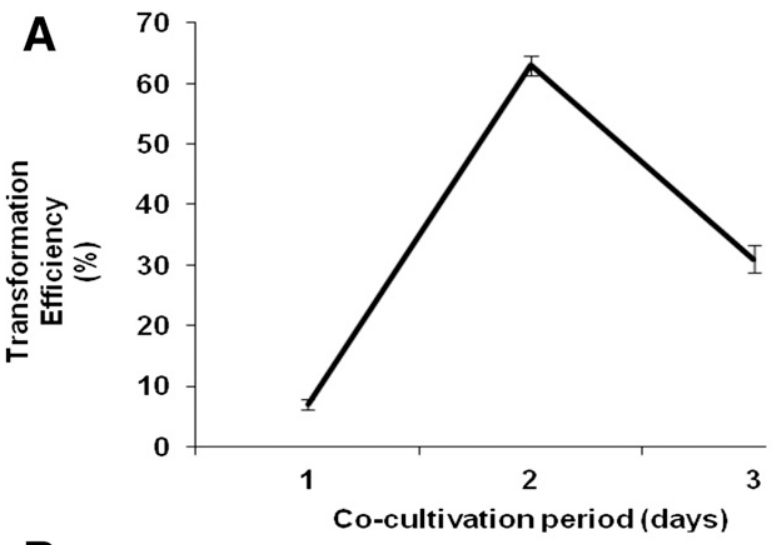

B
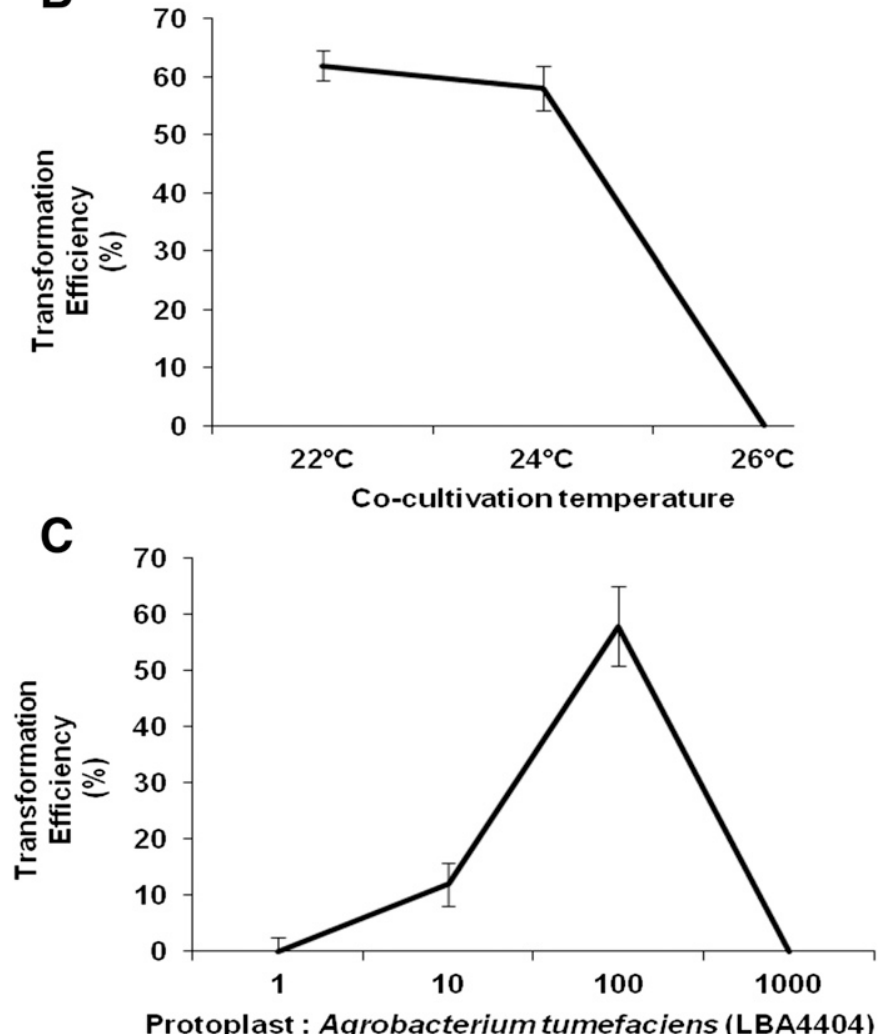

Fig. 1. Cocultivation conditions for Ganoderma boninense transformant derived from Agrobacterium LBA4404 and protoplast mixture. Transformation efficiency at different $\mathbf{A}$, cocultivation periods; $\mathbf{B}$, cocultivation temperatures; and $\mathbf{C}$, explant/Agrobacterium ratios. All transformation conditions used were as follows, unless stated otherwise: Agrobacterium LBA4404/protoplast (1:100) mixture incubated for 2 days at $22^{\circ} \mathrm{C}$ on induction medium prior to selection. transformants were able to produce mycelia better when grown on PGA compared with PDA (Supplementary Fig. S2). The regeneration efficiency for mycelium-derived transformants could not be further optimized.

Transformant: Integration and expression analysis. The binary vector pCAMBIA1304 allows dual selection of transformants based on $\beta$-glucuronidase (GUS) staining and GFP fluorescence. In this study, only the GFP activity was monitored.

Successful integration of marker genes (Hyg and gus-gfp fusion) in transformants derived from protoplast-Agrobacterium LBA4404, basidiospore-GV3101, and mycelium-EHA101 was detected in the F1 generation (Fig. 2).

The GFP expression by transformants derived from all three explant types was generally inconsistent (Fig. 3). Although GFP distribution was not documented quantitatively, based on our observations, we believe the GFP expression was more uniform in protoplast-Agrobacterium LBA4404-derived transformants (Fig. 3A) compared with basidiospore-Agrobacterium GV3101- (Fig. 3B) and mycelium-Agrobacterium EHA101-derived transformants (Fig. 3C). The GFP expressions of the protoplast- and basidiosporederived transformants remained stable for five subsequent subcultures. All transformants subjected to confocal microscopy were harvested as cubes $(0.5$ by $0.5 \mathrm{~cm})$ from the leading edge of its axenic culture.

Copy number of the GFP fragment from the protoplastAgrobacterium LBA4404-derived transformant was the lowest, with an average of 10 , followed by basidiospore-Agrobacterium GV3101, with an average of 22 and mycelium-Agrobacterium EHA101-derived transformant, with an average of 32 (Fig. 4). Monitoring of early-stage infection of oil palm seedlings was performed using transformants derived from the protoplast-Agrobacterium LBA4404 combination only.

GFP marker in $G$. boninense transformant to discern the early stage infection of BSR. The protoplast-Agrobacterium LBA4404-derived transformant was selected to monitor the early stage of oil palm seedling infection. When inoculated on balls of oil palm root powder, the transformant showed complete colonization

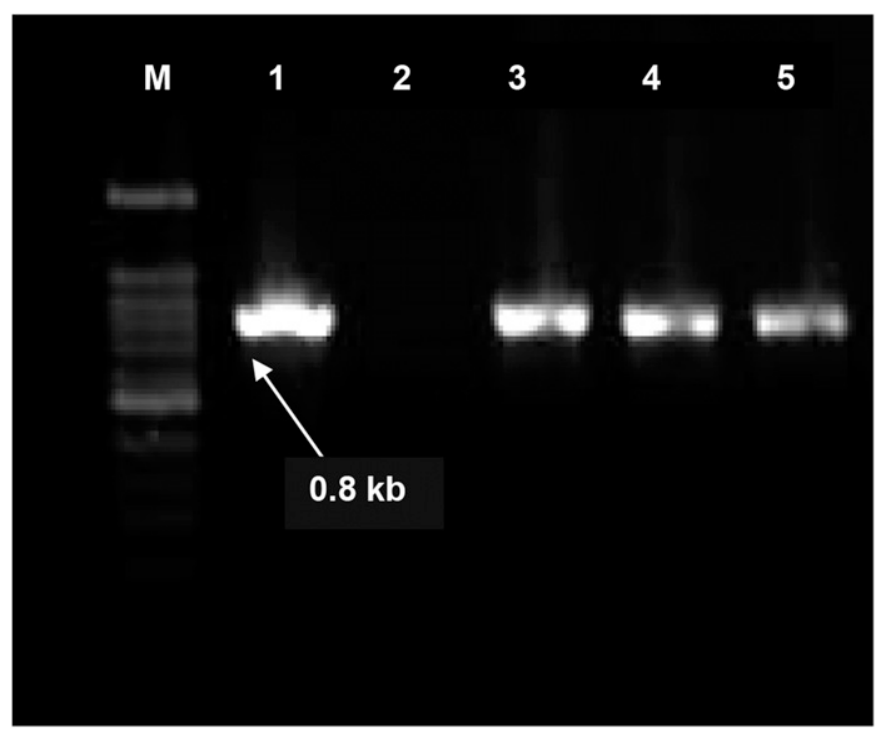

Fig. 2. Polymerase chain reaction detection of the gus-gfp fusion gene within Ganoderma boninense transformants derived from different explant typeAgrobacterium strain combinations. Lane M, DNA size marker (1.5 kb); lane 1, positive control plasmid pCAMBIA 1304; lane 2, negative control wild-type G. boninense; lane 3, basidiospore-Agrobacterium GV3103-derived transformant; lane 4, protoplast-Agrobacterium LBA4404-derived transformant; lane 5, mycelia-Agrobacterium EHA101-derived transformant. Transformation was conducted with a 1:100 Agrobacterium/explant mixture cocultivated on a nitrocellulose membrane overlaid on an induction medium for 2 days at $22^{\circ} \mathrm{C}$, then transferred onto a selection medium and incubated at $28^{\circ} \mathrm{C}$ for a week. 
by day 6 after inoculation (Fig. 5A). The ball-like inoculum appeared to be firmly attached to the root surface of the oil palm plantlets (Fig. 5B) throughout the experiment. At week 1 postinoculation, the oil palm root surface showed no visible symptoms. At week 2 postinoculation, visible fungal hyphae were observed on the root surface. In root cross-sections, the transformant expressing the GFP could be observed. Root autofluorescence showed yellow coloration at the exodermis layer (Fig. 5C). Longitudinal root surface sections and root cross-sections were prepared from and within the area $(<2 \mathrm{~cm})$ of fungal attachments (Fig. 5D).

G. boninense microhyphae, detected as green fluorescence, were observed penetrating the root exodermis layer at random positions (Fig. 5E). The pathogen was found entering in a longitudinal fashion from the epidermis into the exodermis and cortical tissues of the root tissue (Fig. 5F). It appears that penetration by G. boninense begins with the morphogenesis of a needle-like microhyphae. Upon evaluation of the longitudinal root-surface sections (collected at the point of inoculation) under confocal microscopy, the needle-like microhyphae could not be resolved because the GFP fluorescence was too high due to the presence of a dense network of mycelia. However, within 10 to $15 \mathrm{~mm}$ from the point of fungal attachment, the longitudinal root-surface sections showed the presence of needle-like microhyphae in the absence of visible fungal attachment.

\section{DISCUSSION}

We developed an AMT protocol for $G$. boninense based on a revised cocultivation procedure described earlier (Sun et al. 2001). Although this protocol was not compatible for transforming mycelia, both protoplasts and basidiospores could be transformed efficiently. However, it took less time to obtain protoplasts from
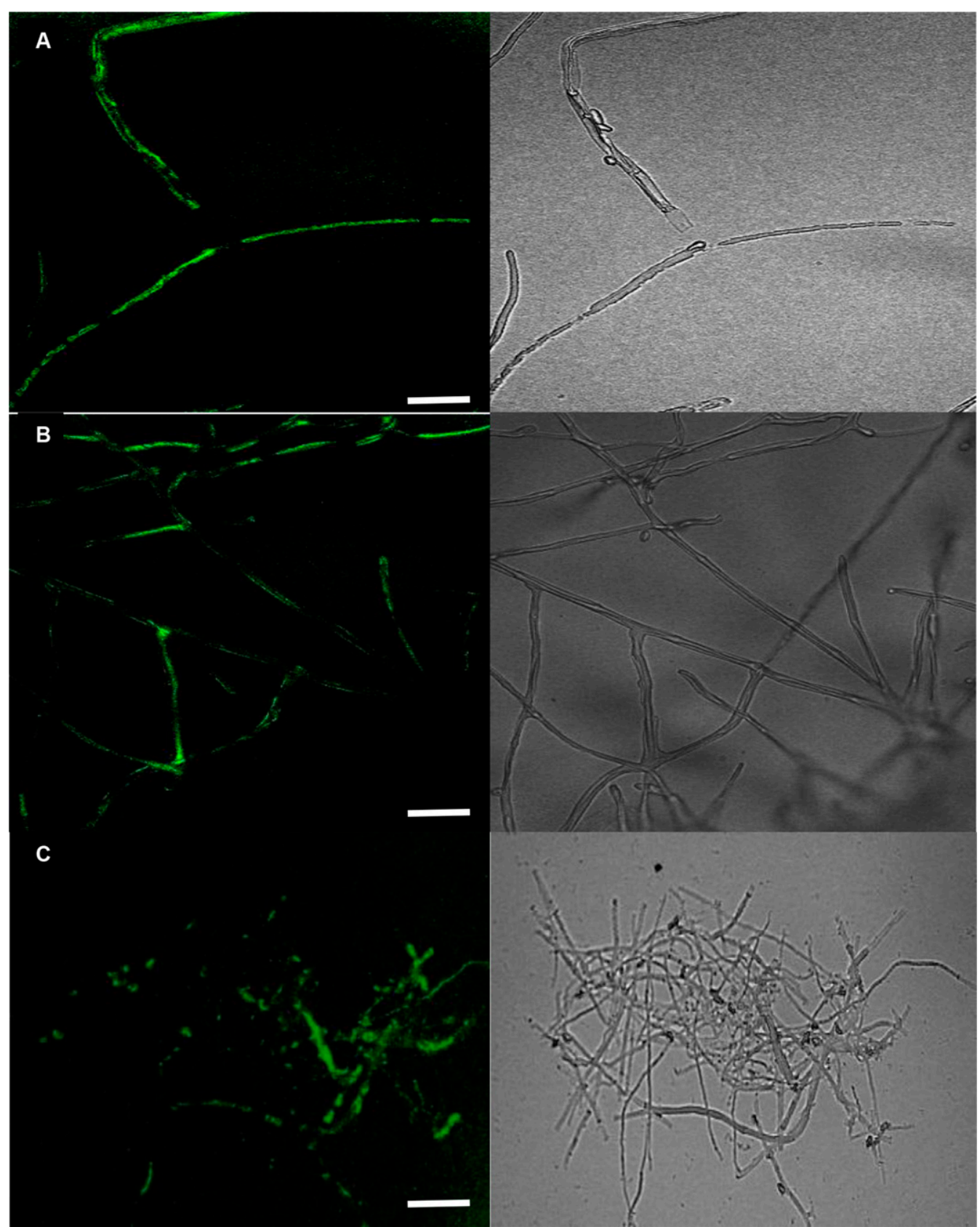

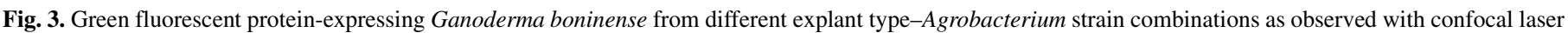

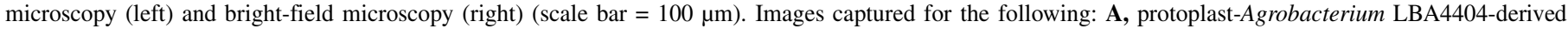
hyphae; B, basidiospore-Agrobacterium GV3101-derived hyphae; and C, mycelia-Agrobacterium EHA101-derived hyphae. 
mycelia cultures than to obtain basidiospores from an artificially produced basidiocarp (approximately 5 to 10 weeks). The T-DNA transfer, which was only possible in the presence of the gpd promoter of fungal origin, was comparable with several other

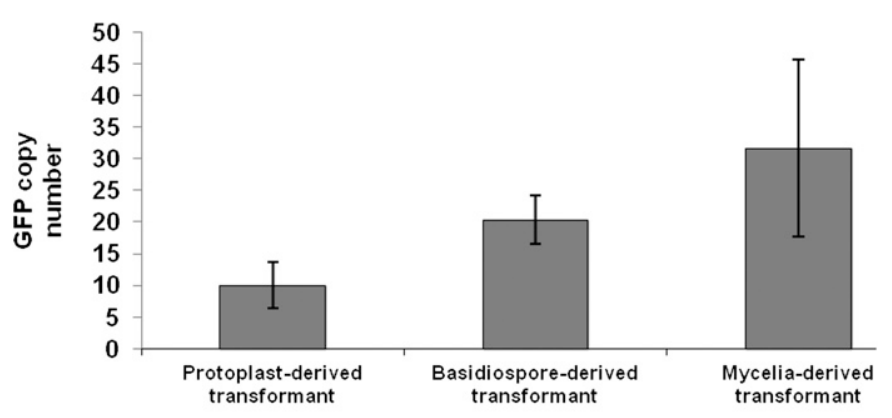

Ganoderma boninense transformant

Fig. 4. Copy number of green fluorescent protein (GFP) transcripts in Ganoderma boninense transformants from different explant type-Agrobacterium strain combinations: protoplast-LBA4404, basidiospore-GV3103, and mycelia-EHA101. The bars represent standard deviation computed from four biological replicates per treatment. All transformations were performed using Agrobacterium/explant at a 1:100 ratio, cocultivated on an induction medium for 2 days at $22^{\circ} \mathrm{C}$ prior to selection. studies (Kuo et al. 2004; Sharma and Kuhad 2010). The Agrobacterium/explant ratio was pivotal to transformation efficiency. In any treatment with a high ratio of either Agrobacterium (1:1) or explant $(1: 1,000)$, transformants failed to regenerate into mycelia. During cocultivation, which excluded the amendment of cefotaxime, an increased Agrobacterium population may have suffocated explants, resulting in poor transformation efficiency. Likewise, an increased fungal population may have interfered with the T-DNA integration into fungal nuclear genome. Our results were comparable with those of Shi et al. (2012), who demonstrated use of a low Agrobacterium/explant ratio for increased transformation efficiency of $G$. lucidum.

Visualization of fungal structures within roots has been demonstrated using fluorescent pathogens harboring selective markers such as GFP and GUS (Rajasekaran et al. 2008; Vallad and Subbarao 2008; Zhang et al. 2013) and our study demonstrated the same with $G$. boninense. The BSR time course infection has been well characterized based on cellular changes on oil palm root tissues (Rees et al. 2009). However, in-depth penetration was not evident. Because the disease is asymptomatic during the initial stage of colonization, resolving the penetration event using popular techniques such as conventional staining and transmission electron microscopy did not seem to be a feasible approach. The initial population size of the pathogen during host infection would be relatively small and probably insufficient for efficient staining.

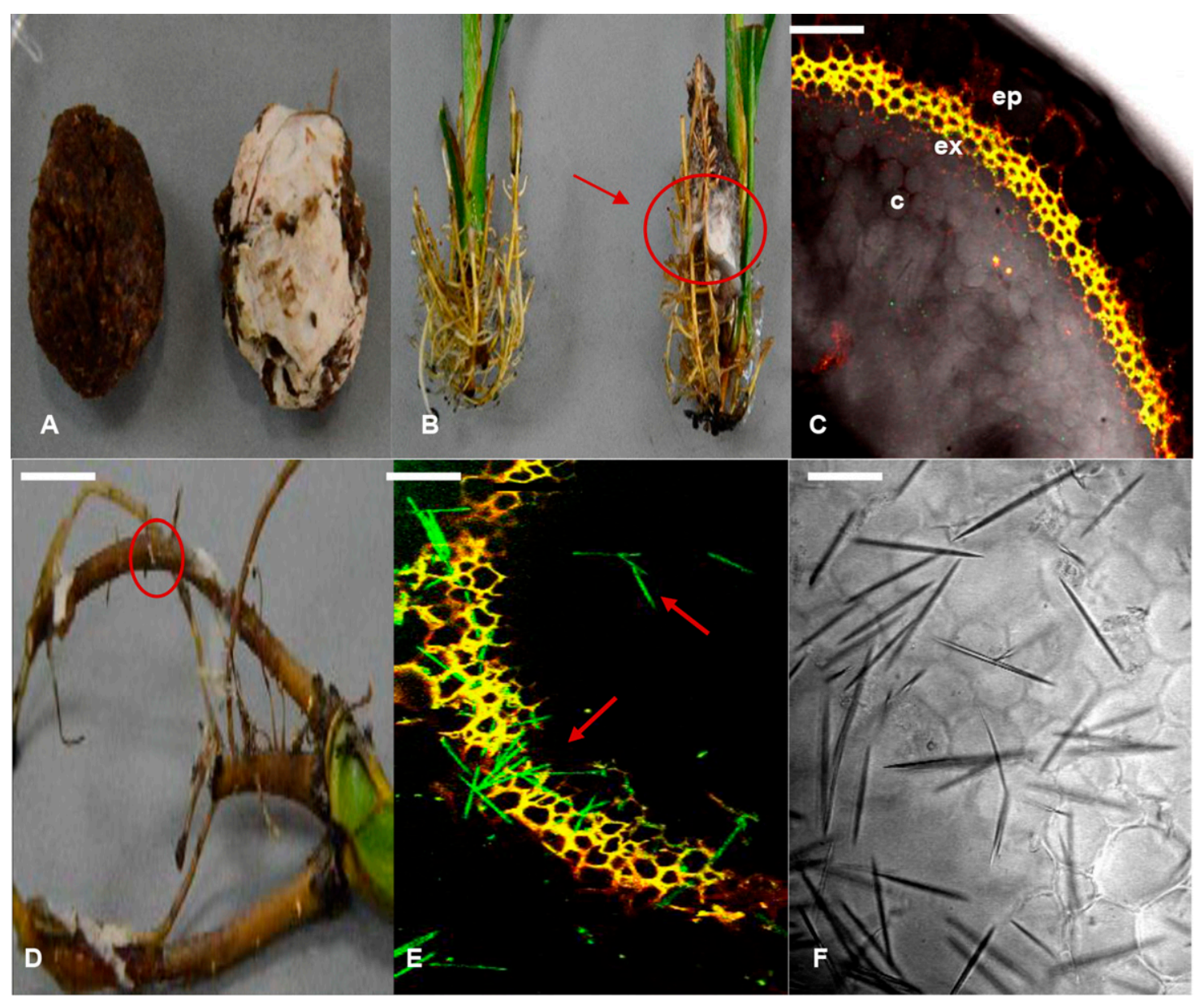

Fig. 5. Green fluorescent protein-expressing Ganoderma boninense for artificial infection of oil palm plantlets. A, Ball-like root medium (left) and G. boninense transformant (derived from protoplast-Agrobacterium LBA4404 combination) colonized inoculum (right). B, Noninoculated (control) oil palm plantlets (left) and infected oil palm plantlets (right) at week 1 postinoculation. Red arrow and circle indicate the attached inoculum. C, Root cross section (control) indicates autofluorescence (yellow signal) of the exodermis (scale bar $=250 \mu \mathrm{m}$ ). D, Infected tissue for longitudinal root surface (circled area) and cross-sectioning (at fungal attachment). E, Longitudinal penetration by microhyphae from epidermis into exodermis and cortex (scale bar $=180 \mu \mathrm{m}$ ). Red arrows indicate the needlelike microhyphae (green fluorescences). F, Microhyphae (phase contrast) invasion at the cortex region of the G. boninense-infected root tissues (scale bar $=$ $100 \mu \mathrm{m})$. 
Moreover, because the pathogen is found within the root tissues, selective tissue-specific dyes are required to aid in localization of the hyaline hyphae. The described transformation protocol for G. boninense enabled the production of GFP-expressing pathogens with good fluorescence and allowed microscopic visualization of small amounts of fungal tissue.

The exodermis layer of the oil palm root was punctured at random positions by GFP-expressing $G$. boninense needle-like microhyphae (Fig. 5E). The exodermis layer was observed to autofluoresce due to the presence of lignin and other phenolic compounds. Although these compounds have been documented as key components in the oil palm defense mechanisms (Paterson 2007), the pathogen (microhyphae) appeared to breach the host's first line of defense effortlessly. Morphogenesis of microhyphae in the fungal kingdom has served various physiological roles. In Neurospora crassa (Trevithick and Galsworthy 1977) and Fusarium oxysporum (Charest et al. 2004), microhyphae were found triggered during growth in the presence of inhibitors. In contrast, Phellinus noxius (Nicole et al. 1995) utilized microhyphae for invasive cell wall colonization during wood degradation. Our study demonstrated apparent morphogenesis of microhyphae during the early-stage infection of BSR. The particularities of the microhyphae utilized by G. boninense-thin fungal cells with discontinuous walls at extended long distances in the host-were in agreement with other colonization studies (Charest et al. 2004; Ouellette and Baayen 2000; Ouellette et al. 1999, 2002). Microhyphae with thin, imperceptible walls with only certain normal cytoplasmic components (Ouellette et al. 1999) are model organisms for enzyme secretion studies (Ouellette and Baayen 2000). G. boninense is a white rot fungi which uses ligninmodifying enzymes such as laccase, manganese peroxidase, and lignin peroxidase for decomposition of the wood components (Lundell et al. 2010). Although the BSR infection begins with a tight host-pathogen contact, the enzymes (large globular proteins produced by the pathogen at the site of attachment) fail to diffuse through the plant cell wall. The G. boninense microhyphae, which efficiently punctures the host cell wall, bypasses the need for enzyme diffusion.

Breeding for resistance is a far-reaching approach for managing BSR disease. Host resistance corresponds to either an arrested fungal penetration into the host cell or the complete inhibition of fungal colonization at the expense of the host (Hammond-Kosack and Jones 1997). The former impedes host-pathogen surface contact whereas the latter requires a systemic host defense response, functional only in the presence of a resistant genetic make-up. Impeding the penetration event would serve as a better BSR knock-out strategy, as opposed to the subsequent colonization event. For instance, application of compounds which are antagonist against the penetration structure could ultimately block the pathogen-host contact. Resistance to BSR is yet to be reported. However, planting materials with variable degrees of tolerance have been characterized: 'Dura' $\times$ Dura and 'Deli' $\times$ Deli are most susceptible to BSR, whereas Dura $\times$ 'Psifera' and 'Zaire' $\times$ 'Cameroon' are considerably tolerant to BSR (Idris and Ariffin 2004). Genetically modified oil palm promises resistance; though it is possible, nevertheless, it is rather impractical to perform large-scale replanting of already existing plantations. Thus, resolving the penetration event contributes to efficient management strategies which could ultimately result in significant economic impacts to the oil palm industry. Our study is the first to demonstrate a reliable and highly efficient system for transformation of $G$. boninense. The results obtained demonstrated the applicability of GFP-expressing G. boninense as a model system for the study of BSR. The GFPexpressing transformant, together with the artificial infection of oil palm plantlets, could also be used for real-time assessment of fungicides, bio-control agents, and other strategies to suppress BSR disease. Preliminary results could be achieved in a shorter period of time in comparison with conventional glasshouse and field trials, which are time consuming.

\section{ACKNOWLEDGMENTS}

We thank the Ministry of Higher Education (MOHE), Malaysia for providing Fundamental Research Grant Scheme, and Applied Agricultural Resources, Petaling Jaya, Selangor for partially financing this study. We thank I. A. Seman from the Malaysian Palm Oil Board (MPOB) for providing oil palm plantlets and M. Mahmood (Universiti Putra Malaysia) and W. H. Ling (Universiti Tunku Abdul Rahman, Malaysia) for their technical support. N. Govender was supported by a MyBrain Ph.D. scholarship sponsored by MOHE, Malaysia

\section{LITERATURE CITED}

Ali, S., and Bakkeren, S. 2011. Introduction of large DNA inserts into the barley pathogenic fungus, Ustilago hordei, via recombined binary BAC vectors and Agrobacterium-mediated transformation. Curr. Genet. 57:63-73.

Ariffin, D., Idris, A. S., and Singh, G. 2000. Status of Ganoderma in oil palm. Pages 49-68 in: Ganoderma Diseases of Perennial Crops. J. Flood, P. D. Bridge, and M. Holderness, eds. CABI Publishing, Wallingford, UK.

Charest, P. M., Ouellette, G. B., Blais, P., and Chamberl, H. 2004. Irregular growth forms and cell wall modifications, polygalacturonase detection, and endocell formation in Fusarium oxysporum f. sp. radicis-lycopersici infecting tomato plants, as studied ultrastructurally and cytochemically. Mycol. Prog. 3:137-150.

Chou, T. H., and Tzean, S. S. 2016. Protoplasting, regeneration and transformation of medicinal mushroom Ganoderma multipileum using succinate dehydrogenase mutation gene as a selection marker. Ann. Microbiol. 66:111-120.

Dorak, M. T. 2007. Real-time PCR. Online publication. Taylor and Francis Group. http://www.gene-quantification.com/dorak-book-real-time-pcr-2006.pdf

Govender, N. T., Mahmood, M., Seman, I. A., and Wong, M. Y. 2016. Basidiospore and protoplast regeneration from raised fruiting bodies of pathogenic Ganoderma boninense. Pol. J. Microbiol. 65:383-388.

Hammond-Kosack, K. E., and Jones, J. D. G. 1997. Plant disease resistance genes. Annu. Rev. Plant Physiol. Plant Mol. Biol. 48:575-607.

Ho, Y. W., and Nawawi, A. 1985. Ganoderma boninense Pat. from basal stem rot of oil palm (Elaeis guineensis) in Peninsular Malaysia. Pertanika $8: 425-428$

Idris, A. S., and Ariffin, D. 2004. Basal Stem Rot-Biology, Detection and Control. Paper number 9 in: Int. Conf. Pest Dis. Importance Palm Industry, Kuala Lumpur, Malaysia.

Kuo, C. Y., Chou, S. Y., and Huang, C. T. 2004. Cloning of glyceraldehydes-3phosphate dehydrogenase gene and use of the gpd promoter for transformation in Flammulina velutipes. Appl. Microbiol. Biotechnol. 65: 593-599.

Li, C. Q., Shao, J. F., Wang, Y. J., Li, W. B., Guo, D. J., Yan, B., Xia, Y., and Peng, M. 2013. Analysis of banana transcriptome and global gene expression profiles in banana roots in response to infection by race 1 and tropical race 4 of Fusarium oxysporum f. sp. cubense. BMC Genomics 14:851.

Lundell, T. K., Makela, M. R., and Hilden, K. 2010. Lignin-modifying enzymes in filamentous basidiomycetes-ecological, functional and phylogenetic review. J. Basic Microbiol. 50:5-20.

Michielse, C. B., Hooykaas, P. J. J., van den Hondel, C. A. M. J. J., and Ram, A. F. J. 2005. Agrobacterium-mediated transformation as a tool for functional genomics in fungi. Curr. Genet. 48:1-17.

Mora-Lugo, R., Zimmermann, J., Rizk, A. M., and Fernandez-Lahore, M. 2014. Development of a transformation system Aspergillus sojae based on the Agrobacterium tumefaciens-mediated approach. BMC Microbiol. $14: 247$.

Mumberg, D., Muller, R., and Funk, M. 1995. Yeast vectors for the controlled expression of heterologous proteins in different genetic backgrounds. Gene 156:119-122.

Nicole, M., Chamberland, H., Rioux, D., Xixuan, X., Blanchette, R. A., Geiger, J. P., and Ouellette, G. B. 1995. Wood degradation by Phellinus noxius: Ultrastructure and cytochemistry. Can. J. Microbiol. 41:253-265.

Ouellette, G. B., and Baayen, R. P. 2000. Peculiar structures occurring in vessel walls of the susceptible carnation cultivar Early Sam infected with Fusarium oxysporum f. sp. dianthi. Can. J. Bot. 78:270-277.

Ouellette, G. B., Baayen, R. P., Simard, M., and Rioux, D. 1999. Ultrastructural and cytochemical study of colonization of xylem vessel elements of susceptible and resistant Dianthus caryophyllus by Fusarium oxysporum f. sp. dianthi. Can. J. Bot. 77:644-663.

Ouellette, G. B., Baayen, R. P., Simard, M., and Rioux, D. 2002. Reactions of paratracheal cells of resistant and susceptible carnation (Dianthus caryophyllus) cultivars to vascular invasion by Fusarium oxysporum f. sp. dianthi. New Phytol. 156:113-128.

Pardo, A. G., Hanif, M., Raudaskoski, M., and Gorfer, M. 2002. Genetic transformation of ectomycorrhizal fungi mediated by Agrobacterium tumefaciens. Mycol. Res. 106:132-137. 
Paterson, R. R. M. 2007. Ganoderma disease of oil palm-A white rot perspective necessary for integrated control. Crop Prot. 26:1369-1376.

Rajasekaran, K., Cary, J. W., Cotty, P. J., and Cleveland, T. E. 2008. Development of a GFP-expressing Aspergillus flavus strain to study fungal invasion, colonization, and resistance in cottonseed. Mycopathologia 165:89-97.

Rees, R. W., Flood, J., Hassan, Y., Potterd, U., and Cooper, R. M. 2009. Basal stem rot of oil palm (Elaies guineensis): Mode of infection and lower stem invasion by Ganoderma boninense. Plant Pathol. 58:982-989.

Sharma, K. K., and Kuhad, R. C. 2010. Genetic transformation of lignin degrading fungi facilitated by Agrobacterium tumefaciens. BMC Biotechnol. 10:67.

Shi, L., Fang, X., Li, M. J., Mu, D., Ren, A., Tan, Q., and Zhao, M. 2012. Development of a simple and efficient transformation system for the basidiomycetous medicinal fungus Ganoderma lucidum. World J. Microbiol. Biotechnol. 28:283-291.

Sun, L., Cai, H., Xu, W. H., Hu, Y., Gao, Y., and Lin, Z. 2001. Efficient transformation of the medicinal mushroom Ganoderma lucidum. Plant Mol. Biol. Rep. 19:383-384.

Sundram, S., Sariah, M., Idris, A. S., and Radziah, O. 2011. Symbiotic interaction of endophytic bacteria with arbuscular mycorrhizal fungi and its antagonistic effect on Ganoderma boninense. J. Microbiol. 49:551-557.

Tarmizi, A. H. 2002. Oil palm liquid culture-MPOB Protocol. MPOB Information Series. ISSN 1511-7871. Malaysian Palm Oil Board, Bangi Selangor, Malaysia.

Thompson, A. 1931. Stem rot of the oil palm in Malaya. Bull. Dep. Agric. Sci. Ser. 23. Department of Agriculture, Malaysia.

Trevithick, J. R., and Galsworthy, P. R. 1977. Morphology of slime variants of Neurospora crassa growing on a glass surface in liquid medium. Arch. Microbiol. 115:109-118.
Turner, P. D. 1981. Page 280 in: Oil Palm Diseases and Disorders. Oxford University Press, Kuala Lumpur, Malaysia.

Turner, P. D., and Gillbanks, R. A. 2003. Oil Palm Cultivation and Management. The Incorporated Society of Planters, Kuala Lumpur, Malaysia.

Utomo, C., Werner, S., Niepold, F., and Deising, H. B. 2005. Identification of Ganoderma, the causal agent of basal stem rot disease in oil palm using a molecular method. Mycopathologia 159:159-170.

Vallad, G. E., and Subbarao, K. V. 2008. Colonization of resistant and susceptible lettuce cultivars by a green florescent protein-tagged isolate of Verticillium dahliae. Phytopathology 98:871-885.

Wang, J., Guo, L. Q., Zhang, K., and Lin, J. F. 2008. Highly efficient Agrobacterium-mediated transformation of Volvariella volvacea. Bioresour. Technol. 99:8524-8527.

Wang, Y., DiGuistini, S., Wang, T. T., Bohlmann, J., and Breuil, C. 2010. Agrobacterium-meditated gene disruption using split-marker in Grosmannia clavigera, a mountain pine beetle associated pathogen. Curr. Genet. 56: 297-307.

Zhang, W. W., Jiang, T. F., Cui, X., Qi, F. J., and Jian, G. L. 2013. Colonization in cotton plants by a green fluorescent protein labelled strain of Verticillium dahlia. Eur. J. Plant Pathol. 135:867-876.

Zhou, Y. P., Chen, M. H., Lu, J. J., Kang, X., Chen, Q. H., Huang, X. L., and Tian, C. E. 2015. A simple and efficient genetic transformation method of Ganoderma weberianum. Folia Microbiol. (Praha) 60:417-423.

Zhu, J., Oger, P. M., Schrammeijer, B., Hooykaas, P., Farrand, S. K., and Winnans, S. 2000. The bases of crown gall tumorgenesis. J. Bacteriol. 182: 3885-3895. 